\title{
Impact of a behaviourally focused nutrition education intervention on attitudes and practices related to eating habits and activity levels in Indian adolescents
}

\author{
Panchali Moitra ${ }^{1, *}{ }^{(0)}$, Jagmeet Madan ${ }^{1}$ and Preeti Verma ${ }^{2}$ \\ 'Department of Food, Nutrition \& Dietetics, Sir Vithaldas Thackersey College of Home Science (Autonomous), SNDT \\ Women's University, Santacruz West, Mumbai 400049, India: ${ }^{2}$ Department of Special Education, SNDT Women's \\ University, Juhu, Mumbai, India
}

Submitted 12 May 2020: Final revision received 23 December 2020: Accepted 14 January 2021: First published online 20 January 2021

\begin{abstract}
Objective: To evaluate the effectiveness of a behaviourally focused nutrition education (NE) intervention based on the Health Belief Model (HBM) to improve knowledge, attitudes and practices (KAP) related to eating habits and activity levels in 10-12-year-old adolescents in Mumbai, India.

Design: School-based cluster randomised controlled trial. The experimental group (EG) received weekly NE and three parent sessions over 12 weeks; no sessions were conducted for the control group (CG). The theoretical framework of HBM and focus group discussion results guided the development of behaviour change communication strategies and NE aids. KAP were measured using a validated survey instrument, administered at baseline and endline in EG and CG. Paired and independent $t$ tests determined within-group and between-group changes in pre-post scores.

Setting: Two aided and two private schools that were randomly allocated to either an EG or CG.

Participants: Adolescent boys and girls ( $n$ 498; EG $n 292$ and CG $n$ 206).

Results: EG reported improvements in mean knowledge (39.3\%), attitude (7.3\%), diet (9.6\%) and activity practice (9.4\%) scores from pre to post intervention. No significant changes were observed in CG. Significant improvements in scores associated with perceived benefits, barriers and self-efficacy, breakfast and vegetable consumption, and moderate-to-vigorous activities were observed in EG.

Conclusions: Integrating NE into the academic curriculum and adopting evidencebased lessons that entail targeted information delivery and participatory activities can improve knowledge, foster right attitudes and facilitate better eating and activity-related practices in Indian adolescents.
\end{abstract}

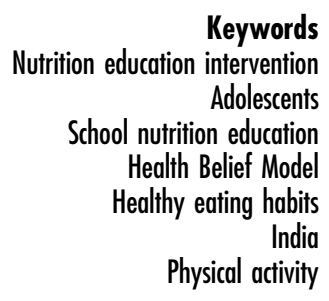

Adolescence is an opportune period of life when interventions that promote healthy behaviours and prevent the risk of lifestyle-related chronic diseases in later life gain prominence $^{(1-3)}$. It is during these years that adolescents start to make their own choices and can be molded to assume responsibility for their actions and form positive habits that will improve their present and long-term health ${ }^{(4,5)}$. Lifestyle choices are often guided by misleading information and adolescents may not appreciate the links between eating habits, physical activity levels and future health consequences ${ }^{(6-8)}$. Therefore, it is prudent that health-promoting interventions for adolescents focus on the attainment of adequate knowledge, enhancement of

the right attitudes towards desired health behaviours, and building of skills and self-efficacy to take appropriate actions.

Unhealthy eating behaviours such as skipping meals, high intake of energy-dense and nutrient-deficient foods such as wafers, chocolates and sweetened beverages, frequent consumption of fast foods and inadequate intake of protective foods such as fruits and vegetables have been reported in adolescents in India, as elsewhere ${ }^{(9-13)}$. Besides changes in dietary patterns, there is evidence that a substantial proportion of adolescents do not meet the current WHO recommendations of accumulating at least $60 \mathrm{~min}$ of moderate-to-vigorous physical activity every 
day and limiting the daily screen time to below $2 \mathrm{~h}^{(14-17)}$. Recent studies in India have reported insufficient physical activity levels and prolonged screen time in urban schoolgoing adolescents ${ }^{(18-21)}$. These changes in eating habits and activity levels may lend to inadequate nutrition (deficits or excess), long-term growth, development and health consequences and potentially cumulate as risk factors to trigger an early onset of metabolic derangements such as obesity and insulin resistance and other lifestyle-related noncommunicable diseases in adolescents ${ }^{(22-26)}$

A general lack of knowledge regarding nutrition and activity recommendations among adolescents, as reported in several studies ${ }^{(27-31)}$, accentuates the need to build awareness and skills as prerequisites for promoting desirable nutrition and activity behaviours. Nutrition education (NE) including physical activity promotion is an effective strategy to bring increments in knowledge and tailor adjustments to eating behaviours and activity patterns ${ }^{(32-34)}$. Schools work as perfect settings to deliver health-promoting information $^{(34-36)}$, so school-based $\mathrm{NE}$ interventions can prove instrumental in encouraging healthy eating habits $^{(30,37,38)}$ and activity practices among adolescents ${ }^{(34,39,40)}$.

While NE generally works to disseminate meaningful information, studies have observed that gains in knowledge may not necessarily translate into attitudinal and behavioural changes unless efforts are made to motivate the target group and the learning experiences are carefully focused to facilitate behavioural changes ${ }^{(41-44)}$. A systematic review observed that NE programmes with successful outcomes were more likely to be behaviourally focused and were more effective when driven by theories to develop developmentally and culturally appropriate behaviour change strategies ${ }^{(45)}$.

The Health Belief Model (HBM) is a conceptual framework that has been used in several studies to understand health-related behaviours and guide behaviour change interventions ${ }^{(46-49)}$. The constructs of this model, namely perceived susceptibility, severity, perceived benefits and barriers, and cues to take health action, can be employed to inform content and communication strategies for $\mathrm{NE}$ programmes $^{(48,50)}$.

The current Indian secondary school curriculum includes health and NE as a part of the science or physical education syllabus, although limited exposure to nutritionrelated content and lack of relevant practical skills-based assignments to encourage positive behaviour change have been reported ${ }^{(8,51)}$. A curriculum-based NE intervention that provides relevant knowledge in a fun and interesting way $^{(32)}$, promotes attitudes and skills conducive to good health ${ }^{(46)}$, involves parents as partners ${ }^{(52)}$ and features participatory activities tailored to the needs of the target group $^{(53)}$ can make a significant contribution to improving diet and activity practices and thereby reducing the risk to rampant issues such as obesity among adolescents ${ }^{(37,54,55)}$.

The current study attempted to address the lacunae in the area of theory-driven NE interventions in adolescents in India. The objectives of the current study were two-fold - first, to develop NE modules based on the key constructs of the HBM targeted at early adolescents (10-12 years) and their parents and second, to evaluate the changes in knowledge, attitudes and practices (KAP) related to eating habits and activity levels among adolescents who participated in the classroom-based, behaviourally focused NE intervention compared with those who did not.

\section{Methods}

\section{Setting and participants}

This school-based cluster randomised controlled trial was conducted among 10-12-year-old adolescents studying in grades 6 and 7 of two coeducational private and two coeducational aided schools in the metropolitan city of Mumbai in western India. While the aided schools are government-funded and typically cater to families that belong to low and low middle-class socio-economic status (SES), private schools are supported by private managements and are usually attended by students belonging to uppermiddle and high SES. Out of the four selected schools, one private school and one aided school were randomly assigned to be the experimental schools by tossing a coin, and the other two schools (one private and one aided school) were designated as the control schools. Selection of schools using the cluster randomisation method ensured that there was a proportional representation from each type of school (private or aided school, used as a proxy for SES) in the control group (CG) and experimental group (EG).

All students studying in grades 6 and 7 of the selected private schools ( $n$ 366) and aided schools ( $n$ 318) were eligible to participate. Out of 684 eligible participants, 166 were excluded due to either non-receipt of signed parent consent forms ( $n$ 102), incomplete information ( $n$ 41) or absence on the baseline survey day ( $n$ 23). A total of 518 participants provided written, informed parental consent, and written assent and comprised the final sample. The detail of the selection process of participants in the study is provided in Fig. 1.

\section{Sample size estimation}

The sample size was calculated using the effect size estimates of the difference in means between two independent groups with regard to dietary practice as the primary outcome variable, considering a significance level (two-tailed) of 0.05 and a statistical power of $80 \%$. Based on recent systematic reviews of studies aimed at determining the impact of NE interventions on nutritional knowledge and fruit, vegetable and sugar consumption among adolescents $^{(38,56,57)}$, we estimated the effect size of $0 \cdot 3$ as a measure of treatment effect. Using the simplified formula, $n$ 16/ $\delta^{2}$, where $\delta$ represents the standardised effect size ${ }^{(57,58)}$, the required sample size was calculated as 178 in each 


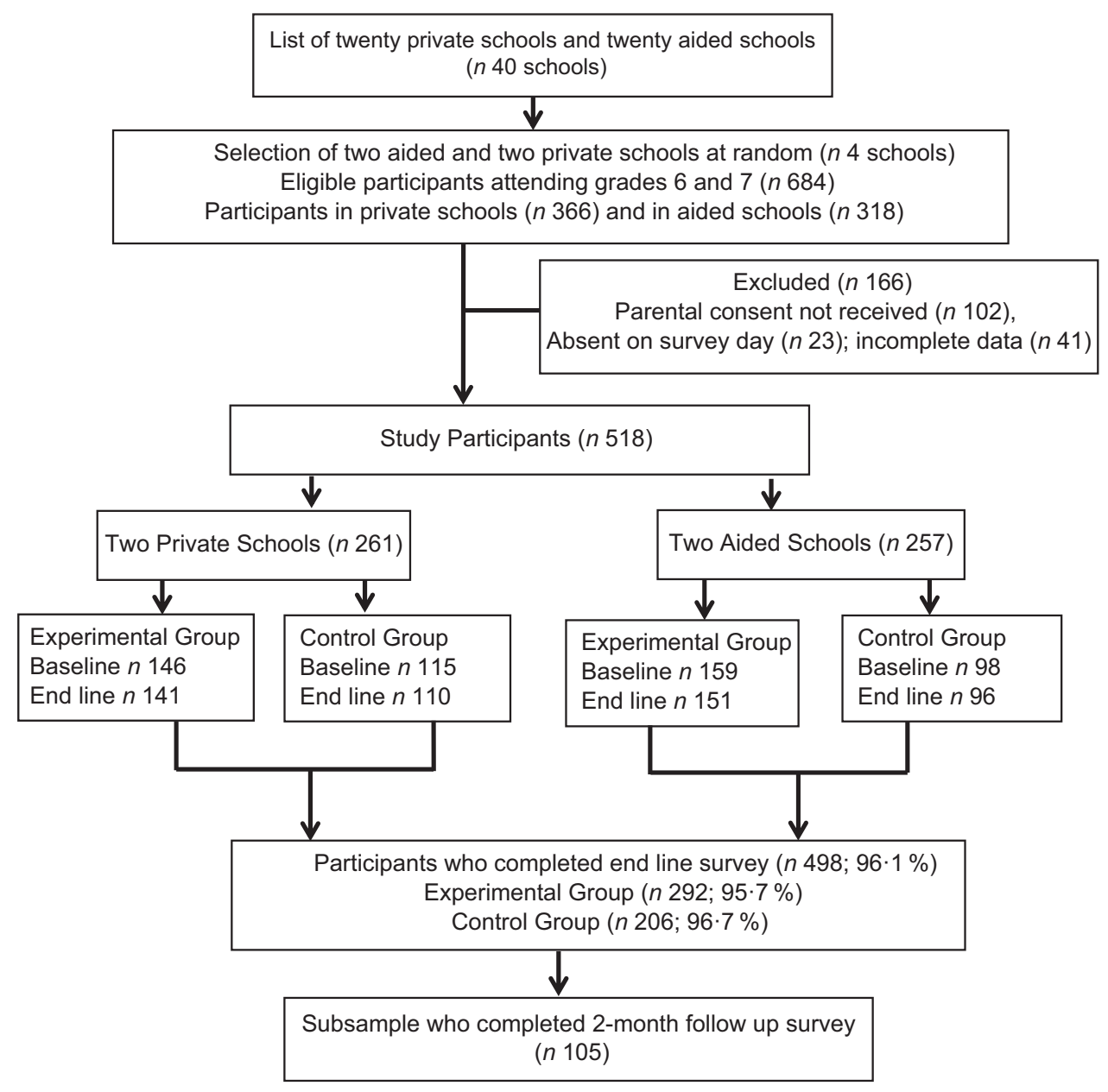

Fig. 1 Method of selection of study participants

comparison group. Considering a non-response rate of $20 \%$, as indicated in previous studies $(33,59,60)$, the total sample size for the study was estimated as 214 $(\mathrm{EG})+214(\mathrm{CG})=428$.

\section{Study phases}

The study was conducted in three phases - the first phase involved conducting a series of focus group discussions with key stakeholders - adolescents, parents and teachers as formative research to understand the attitudes and perceptions towards healthy eating and physical activity levels among adolescents and to get insights regarding the development of NE aids and messages for the education intervention. The detailed description of the focus group results is described elsewhere ${ }^{(61)}$. The second phase involved the development of a survey instrument measuring KAP and testing the validity and reliability using a crosssectional study design ${ }^{(62)}$. The third phase involved designing NE lesson plans, education materials and teaching aids followed by recruitment and randomisation of schools into experimental and control schools, implementation of the NE intervention in experimental schools and pre- to post-intervention assessments.

\section{Data collection instrument and measures}

An eighty-four-item self-designed and validated survey instrument was used to measure KAP at baseline and after 12 weeks in the EG and CG. The questions in the knowledge scale of the instrument included knowledge regarding food groups and nutrients, healthy eating guidelines, risk factors of obesity, diabetes and heart diseases, recommended physical activity levels and allowed daily screen time. Each correct knowledge item was scored +1 and incorrect/do not know responses were scored 0 .

Attitude items included statements that evaluated the HBM constructs-perceived susceptibility and severity to adverse consequences of unhealthy eating habits and physical inactivity, perceived barriers and benefits of healthy behaviours, readiness to change and self-efficacy to adopt these desired behaviour changes. The responses were assessed on a four-point Likert scale (strongly disagree to strongly agree, numeric scores 0 to 3). Dietary practice items evaluated adolescents' eating habits (meal skipping, breakfast consumption, and frequency and type of foods carried in the lunch box to school), family dietary habits (weekly frequency of eating out, ordering takeaways, eating while watching television and eating family 
meals together) and weekly consumption of fruits, vegetables and foods high in salt, sugar and fat using a 24-item FFQ. The response options of 'none', '1-2 d', '3-4d', '5-6 d' and 'every day' were scored from 0 to 4 for fruit and vegetable items and from 4 to 0 for unhealthy snack items to ensure that the higher scores indicated healthier food consumption patterns. Furthermore, we converted the weekly frequencies of consumption of each food item to a daily equivalent in grams using conversion factors as reported in previous studies ${ }^{(11,63)}$

Similarly, the practices related to activity levels were measured by recording the weekly frequency of performing moderate-to-vigorous physical activity and sedentary activities. Adolescents were asked In the last 7 days, bow many days did you engage in any of the following activities? and the scores obtained for each moderate-to-vigorous physical activity and sedentary activity practice item were combined to derive 'overall physical activity' and 'overall sedentary activity' scores, respectively.

The psychometric properties of the instrument were evaluated using face validity, expert content validity (item content validity indices were calculated), construct validity (using principal axis method of exploratory factor analysis), internal consistency (Cronbach $\alpha$ value $>0.7$ ) and testretest reliability (intraclass correlation coefficient values $>0.75)$. Item difficulty and discrimination index were also calculated for knowledge items. The instrument showed good internal consistency and acceptable to good testretest reliability; the item content validity indices for clarity and relevance were also satisfactory.

To evaluate the participants' rating of education materials and instruction effectiveness, a brief six-item feedback questionnaire was administered at the end of 12 weeks in EG. The items measured participant satisfaction, the experience of the lesson contents and teaching methods, instructor's personal and professional attributes, and participants' confidence in adopting desired behaviours. The responses were assessed on a five-point Likert scale from 'strongly disagree' to 'strongly agree'. Two open-ended questions seeking suggestions for topics that could have been done better and the activities that they enjoyed the most were also included in the questionnaire.

\section{Nutrition education materials and lesson plans}

Participants in EG received sessions as part of the schoolbased NE and behaviour change programme referred to as Health Eating and Activity Program for Schoolchildren or in short HEAPS. The theoretical framework of the HBM, results of focus group discussions and dietary guidelines provided by the National Institute of Nutrition, India ${ }^{(64)}$ guided the development of behaviour change goals and education materials. An activity book, 'Eat Right and Move More: A Workbook', was developed as a resource guide to reinforce the importance of healthy eating and being active in adolescents.
The book included twelve chapters, namely Give me 5 (about food groups and balanced diet guidelines), Meet the Biggies (about macronutrients), ABC of Vitamins and Minerals (about key vitamins and minerals required for a growing child), How Healthy are my Eating Habits (related to perceived susceptibility and benefits), Am I at Risk and Break the Barrier (related to perceived severity and barriers), Power Pack your Day (about ways to create simple healthy lunch boxes), Be a Smart Snacker (about the concept of traffic light foods and tips to plan right snacks at right times for right activities), Diet and Diseases (introduction to diabetes and obesity - risk factors, symptoms and health consequences), Hearty Habits for a Healthy Heart (what are heart diseases, why do we get them and how to avoid them), Hop, Run, Dance E Play (regarding the benefits of being active) and more. All participants in EG received a copy of the book, as a part of the intervention programme.

To increase engagement and interest among participants, a variety of interactive educational materials such as posters, presentations, videos, games and crossword puzzles and participatory activities such as recipe competitions, lunch box monitor, Be an Ambassador (hands-on activity to be a spokesperson for nutrition and fitness), Be Food Wise (nutrition label sleuth), Rate the Plate and more were developed and implemented. Lessons were also planned to improve knowledge and attitudes towards physical activity levels using infographics on the benefits of being active, worksheets on the recommended guidelines for sedentary and moderate-to-vigorous physical activity levels, activity pyramids to suggest strategies to sneak in physical activities and role-play skits to show how to beat inactivity (sedentary behaviour and excess screen time-related modules). Three structured physical activity sessions such as 20-m shuttle runs or beep tests during PE classes were conducted and various hands-on assignments such as activity diary, and competitions like Be a Fitness Guru and Recess Activity Cop were included to facilitate improvements in KAP related to activity patterns in adolescents.

Besides taking classes with adolescents, three monthly sessions were conducted for the parents at each experimental school to improve their knowledge about healthy eating behaviours and activity recommendations, to suggest ways to incorporate simple changes in their child's diet and activity routine and to foster a supportive home nutrition environment.

\section{Intervention}

Participants in the experimental schools received weekly classroom-based NE and three parent education sessions over 12 weeks. The NE classes were conducted as part of the academic curriculum (one class of 50-60 min every week) for all students, including those who had not provided parental consent or completed the pre-intervention survey. However, these students were excluded from data collection. No NE sessions were conducted for the control school participants. All 
eligible participants completed a KAP questionnaire at baseline and after 12 weeks. A subgroup of 105 participants (fiftyeight from the private school and forty-seven attending aided school) from experimental schools completed the same KAP questionnaire after 2 months of completion of the education sessions.

The details of the NE intervention based on the constructs of the HBM are provided in online supplementary material, Supplemental Table 1.

\section{Statistical analysis}

Data were analysed using the IBM SPSS Statistics for Windows version 21.0 software. The initial normality test was carried out using Kolmogorov-Smirnov statistics. The demographic characteristics of the EG and CG were compared at baseline using $\chi^{2}$ tests and the results were described as mean and SD for continuous variables and as number and percentages for categorical variables. Within-group and between-group changes in mean KAP scores and mean KAP subscale scores from baseline to 12- week follow-up were assessed using paired and independent $t$ tests, respectively. The tests were two-tailed and a $P$-value of $<0.05$ was considered statistically significant. Repeated measures ANOVA was used to report changes in mean KAP scores from baseline to 12 weeks and 2-month follow-up in EG. Results of participant feedbacks and teacher experiences were derived using content analysis and are reported as anecdotes, quotes and frequency responses.

\section{Results}

\section{Sample characteristics}

A total of 518 adolescents, aged 10-12 years, participated in the baseline survey. Ninety-six percentage of the participants ( $n$ 498; 292 from experimental schools and 206 from control schools) completed the post-intervention survey and comprised the final sample for pre-post comparisons. The mean age of the participants was 11.2 (SD 1.1) years, $48 \%$ were girls and 49.6\% attended aided schools. EG ( $n$ 292) comprised of girls ( $n$ 140) and boys $(n$ 152) and CG $(n$ 206) included 101 boys and 105 girls. No significant differences were observed in baseline demographic variables between EG and CG except in the characteristics religion and father's occupation (Table 1).

\section{Assessment of pre-intervention knowledge, attitude and practice scores}

The proportion of adolescents responding correctly to the knowledge items related to the required servings of fruits and vegetables (33.6\%), allowed sugar consumption (15.6\%), food pyramid (20.7\%), simple and complex carbohydrates (23\%) and recommended daily screen time $(27.8 \%)$ were considerably low. Perceived susceptibility to risk of developing diseases was also observed to be low as 71 and $62 \%$ reported being little worried about getting diabetes and heart diseases, respectively, and $49 \%$ agreed that it is difficult to eat two fruits every day. The responses to perceived barriers to physical activity indicated that 30 and $36 \%$ agreed that they don't get time to exercise and find exercises to be boring, respectively. The majority of participants (72\%) reported carrying lunch boxes to school at least 3-4 times a week, $31 \%$ were skipping breakfast every day and $69 \%$ purchased foods and beverages from their school canteens more than 2-3 times a week. Only $14 \%$ were engaging in any sports such as football, cricket and basketball daily and $71 \%$ reported their daily screen time to be more than $2 \mathrm{~h}$.

\section{Effect of Health Eating and Activity Program for Schoolchildren intervention on knowledge, attitudes and practices scores}

The changes in overall KAP scores from baseline to 12-week follow-up in EG and CG are presented in Table 2. At baseline, no significant differences were observed in the mean knowledge, attitude, dietary and activity-related practice scores between EG and CG. At 12-week follow up, between-group analysis showed that the improvements in knowledge, attitude dietary and physical activity practice scores were significantly higher in EG as compared with CG. The effect sizes (Hedges' g) of $0.455,0.334$ and 0.241 were obtained for attitude, dietary practice and activity-related practices, respectively.

The impact of HEAPS intervention was compared between EG participants who attended aided schools ( $n$ 151) and those who were from private schools (n 141). Within EG, a significantly higher mean change was observed in attitude $(3.38(\mathrm{SD} 5.33)$ in aided $v .2 .01$ (SD 5.12) in private schools; $P=0.026$ ) and physical activity practice $(2.30$ (SD 1.99) in aided $v .1 .41$ (SD 1.77) in private schools; $P<0.001)$ scores in aided school participants as compared with private school participants. The mean pre to post changes in KAP scores were also compared between genders in EG. We observed girls ( $n$ 140) reporting a significantly higher improvement in total knowledge (7.83 (SD 2.7) v. 4.32 (SD 2.1) in boys; $P<0.001)$ and dietary practice scores (5.32 (SD 1.1) v. 4.96 (SD 1.4) in boys; $P=0.016)$ as compared with boys ( $n$ 152).

\section{Effect of intervention on knowledge, attitudes and practices subscale scores}

Table 3 shows the mean pre to post changes in KAP subscale scores between the EG and CG. EG reported a significant improvement in all KAP subscales in the post-intervention assessment as compared with CG, except in the attitude sub-scale of readiness to change, dietary practice subscales of consumption of fruits, high fat foods and high salt foods, and the activity practice subscale related to sedentary activities. The mean KAP 
Table 1 Demographic characteristics of adolescents in the behaviourally focused nutrition education intervention study in Mumbai, India $(n 518)$

\begin{tabular}{|c|c|c|c|c|c|c|c|}
\hline \multirow[b]{2}{*}{ Characteristics } & \multicolumn{2}{|c|}{ Overall $(n 518)$} & \multicolumn{2}{|c|}{$\begin{array}{l}\text { Experimental } \\
\text { group }(n 305 \dagger)\end{array}$} & \multicolumn{2}{|c|}{$\begin{array}{l}\text { Control group } \\
(n 213+)\end{array}$} & \multirow[b]{2}{*}{$P$} \\
\hline & $n$ & $\%$ & $n$ & $\%$ & $n$ & $\%$ & \\
\hline \multicolumn{8}{|l|}{ Gender } \\
\hline Boys & 269 & 51.9 & 165 & $54 \cdot 1$ & 104 & $48 \cdot 8$ & \multirow[t]{2}{*}{0.237} \\
\hline Girls & 249 & $48 \cdot 1$ & 140 & $45 \cdot 9$ & 109 & $51 \cdot 2$ & \\
\hline \multicolumn{8}{|l|}{ Type of school attended } \\
\hline Aided & 257 & $49 \cdot 6$ & 159 & $52 \cdot 1$ & 98 & $46 \cdot 0$ & \multirow[t]{2}{*}{0.17} \\
\hline Private & 261 & $50 \cdot 4$ & 146 & 47.9 & 115 & $54 \cdot 0$ & \\
\hline \multicolumn{8}{|l|}{ Grade in which studying } \\
\hline Sixth & 262 & $50 \cdot 6$ & 146 & 47.9 & 116 & 54.5 & \multirow[t]{2}{*}{0.14} \\
\hline Seventh & 256 & $49 \cdot 4$ & 159 & $52 \cdot 1$ & 97 & $45 \cdot 5$ & \\
\hline \multicolumn{8}{|l|}{ Religion } \\
\hline Hindu & 366 & $70 \cdot 7$ & 192 & 63 & 174 & $81 \cdot 7$ & \multirow{4}{*}{$<0.001^{* *}$} \\
\hline Muslim & 116 & $22 \cdot 4$ & 81 & $26 \cdot 6$ & 35 & $16 \cdot 4$ & \\
\hline Christian & 13 & 2.5 & 11 & 3.6 & 2 & 0.9 & \\
\hline Others & 23 & $3 \cdot 3$ & 21 & 4.9 & 2 & 0.9 & \\
\hline \multicolumn{8}{|l|}{ Father's occupation } \\
\hline Service & 184 & $35 \cdot 5$ & 118 & 38.6 & 66 & 31.0 & \multirow{6}{*}{$<0.001^{* *}$} \\
\hline Business & 175 & 33.8 & 114 & 37.4 & 61 & $28 \cdot 6$ & \\
\hline Professional (doctor/lawyer) & 38 & $7 \cdot 3$ & 12 & 3.9 & 26 & $12 \cdot 2$ & \\
\hline Menial jobs (plumber/painter) & 94 & $18 \cdot 1$ & 57 & 18.7 & 37 & 17.4 & \\
\hline Self-employed & 9 & $1 \cdot 7$ & 1 & 0.3 & 8 & $3 \cdot 8$ & \\
\hline No response & 18 & 3.5 & 3 & 0.9 & 15 & $7 \cdot 0$ & \\
\hline \multicolumn{8}{|l|}{ Mother's working status } \\
\hline Does not work & 314 & $61 \cdot 1$ & 184 & $61 \cdot 1$ & 130 & $61 \cdot 0$ & \multirow{3}{*}{0.083} \\
\hline Part time & 76 & 14.8 & 52 & $17 \cdot 3$ & 24 & 11.3 & \\
\hline Full time & 124 & $24 \cdot 1$ & 65 & $21 \cdot 6$ & 59 & $27 \cdot 7$ & \\
\hline
\end{tabular}

†Data are presented as number and percentages.

${ }^{* *}$ Significant at $P$ value $<0.001$.

Table 2 Changes in the mean knowledge, attitude and practice scores after 12 weeks in the experimental and control group participants $(n 498)$

\begin{tabular}{|c|c|c|c|c|c|c|}
\hline \multirow[b]{2}{*}{ Variables } & \multirow[b]{2}{*}{ Survey period } & \multicolumn{2}{|c|}{$\begin{array}{l}\text { Experimental group } \\
\qquad(n 292)\end{array}$} & \multicolumn{2}{|c|}{ Control group (n 206) } & \multirow[b]{2}{*}{$P+$} \\
\hline & & Mean & SD & Mean & SD & \\
\hline Knowledge & $\begin{array}{l}\text { Pre-intervention } \\
\text { Post-intervention } \\
\% \text { Change } \\
P \text { value } f\end{array}$ & $\begin{array}{l}15.29 \\
21.38 \\
39.80 \% \\
<0.001^{\star \star}\end{array}$ & $\begin{array}{l}4.61 \\
6.03\end{array}$ & $\begin{array}{l}15 \cdot 36 \\
14.55 \\
-5.30 \% \\
0.077\end{array}$ & $\begin{array}{l}5 \cdot 07 \\
4.18\end{array}$ & $\begin{aligned} & 0.802 \\
< & 0.001^{* \star}\end{aligned}$ \\
\hline Attitude & $\begin{array}{l}\text { Pre-intervention } \\
\text { Post-intervention } \\
\% \text { Change } \\
P \text { value } \neq\end{array}$ & $\begin{array}{l}39.59 \\
42.47 \\
7.30 \% \\
<0.001^{\star *}\end{array}$ & $\begin{array}{r}7.38 \\
10.05\end{array}$ & $\begin{array}{c}37.49 \\
38 \cdot 18 \\
1.80 \% \\
0.373\end{array}$ & $\begin{array}{l}7 \cdot 21 \\
8 \cdot 45\end{array}$ & $\begin{aligned} & 0.516 \\
< & 0.001^{* \star}\end{aligned}$ \\
\hline Dietary practice & $\begin{array}{l}\text { Pre-intervention } \\
\text { Post-intervention } \\
\% \text { Change } \\
P \text { value } \neq\end{array}$ & $\begin{array}{l}53.95 \\
59.13 \\
9.60 \% \\
<0.001^{\star *}\end{array}$ & $\begin{array}{r}9.89 \\
14.46\end{array}$ & $\begin{array}{l}55.85 \\
54.64 \\
-2.20 \% \\
0.021^{*}\end{array}$ & $\begin{array}{r}6.41 \\
11.84\end{array}$ & $\begin{array}{l}0.332 \\
0.004^{*}\end{array}$ \\
\hline Activity practice & $\begin{array}{l}\text { Pre-intervention } \\
\text { Post-intervention } \\
\% \text { Change } \\
P \text { valuef }\end{array}$ & $\begin{array}{l}18.44 \\
20.17 \\
9.40 \% \\
<0.001^{\star *}\end{array}$ & $\begin{array}{l}5.08 \\
5.63\end{array}$ & $\begin{array}{l}19 \cdot 48 \\
18 \cdot 88 \\
-3 \cdot 10 \% \\
0.171\end{array}$ & $\begin{array}{l}3.94 \\
4.89\end{array}$ & $\begin{array}{l}0.291 \\
0.008^{*}\end{array}$ \\
\hline
\end{tabular}

${ }^{\star} P$-value $<0.05 ;{ }^{\star \star} P$-value $<0.001$

†Significance level was tested using independent $t$ tests.

$\ddagger$ Significance level was tested using paired $t$ tests.

scores at 2-month follow-up showed significant improvements in knowledge $(28.5 \% ; P<0.001)$, attitude (6.3\%; $P=0.014)$, dietary practice $(4.4 \% ; P=0.041)$ and activity practice $(5.7 \% ; P=0.049)$ scores as compared with the pre-intervention mean KAP scores.

\section{Effect of intervention on the consumption of healthy and unhealthy foods}

At baseline in EG, the mean daily intakes of fruits, green leafy vegetables, chocolates, wafers and carbonated beverages were 18.2 (SD 8.9) g, 40.5 (SD 23.2) g, 20.9 (SD 11.8) g, 
Table 3 Mean change in sub-scale scores of knowledge, attitude and practice in the experimental and control group participants

\begin{tabular}{|c|c|c|c|c|c|c|c|c|c|c|}
\hline \multirow[b]{3}{*}{ Variable } & \multicolumn{5}{|c|}{ Experimental group ( $n$ 292) } & \multicolumn{5}{|c|}{ Control group (n 206) } \\
\hline & \multicolumn{2}{|c|}{ Pre } & \multicolumn{2}{|c|}{ Post } & \multirow[b]{2}{*}{$P$} & \multicolumn{2}{|c|}{ Pre } & \multicolumn{2}{|c|}{ Post } & \multirow[b]{2}{*}{$P$} \\
\hline & Mean & SD & Mean & SD & & Mean & SD & Mean & SD & \\
\hline \multicolumn{11}{|l|}{ Knowledge } \\
\hline Food groups & $1 \cdot 15$ & 0.8 & 1.58 & 0.7 & $<0.001^{\star \star \star}$ & $1 \cdot 10$ & 0.8 & $1 \cdot 14$ & 0.7 & 0.589 \\
\hline $\begin{array}{l}\text { Balanced diet and food } \\
\text { pyramid }\end{array}$ & $1 \cdot 12$ & 0.4 & 1.53 & 0.3 & $<0.001^{\star \star \star}$ & $1 \cdot 18$ & 0.4 & $1 \cdot 19$ & 0.4 & 0.799 \\
\hline Nutrients & 1.72 & $1 \cdot 1$ & $2 \cdot 72$ & 0.9 & $<0.001^{\star \star \star}$ & 2.08 & $1 \cdot 1$ & 1.94 & 0.8 & 0.140 \\
\hline Healthy eating habits & 1.67 & 0.8 & $2 \cdot 41$ & 0.7 & $<0.001^{\star * *}$ & 1.81 & 0.8 & 1.73 & 0.7 & 0.281 \\
\hline Unhealthy eating habits & 2.52 & 1.4 & 3.84 & 0.9 & $<0.001^{\star * *}$ & 2.59 & 1.4 & 2.64 & $1 \cdot 1$ & 0.687 \\
\hline Non communicable diseases & 1.75 & $1 \cdot 1$ & 1.98 & 0.9 & $0.006^{\star *}$ & 1.28 & 0.9 & 1.35 & 0.6 & 0.353 \\
\hline Physical activity pattern & $5 \cdot 32$ & 2.5 & $6 \cdot 15$ & 1.8 & $<0.001^{\star \star \star}$ & $5 \cdot 29$ & $2 \cdot 6$ & 4.98 & $2 \cdot 1$ & 0.183 \\
\hline \multicolumn{11}{|l|}{ Attitude } \\
\hline Perceived severity & $2 \cdot 91$ & 1.6 & $4 \cdot 12$ & $1 \cdot 1$ & $<0.001^{\star \star *}$ & $2 \cdot 78$ & 1.5 & $2 \cdot 72$ & $1 \cdot 2$ & 0.654 \\
\hline Perceived susceptibility & 4.92 & $2 \cdot 6$ & $5 \cdot 61$ & $2 \cdot 8$ & $<0.001^{* * *}$ & $5 \cdot 21$ & $3 \cdot 1$ & $5 \cdot 18$ & $2 \cdot 8$ & 0.918 \\
\hline Perceived benefits & 8.75 & $2 \cdot 8$ & 9.62 & $2 \cdot 6$ & $<0.001^{* * *}$ & 8.55 & 2.5 & 8.88 & $2 \cdot 1$ & 0.148 \\
\hline Perceived barriers & $8 \cdot 80$ & $2 \cdot 8$ & $10 \cdot 64$ & $3 \cdot 1$ & $<0.001^{\star * *}$ & 8.99 & $2 \cdot 1$ & 8.45 & 1.8 & 0.078 \\
\hline Readiness to change & 4.08 & 1.4 & $4 \cdot 19$ & 1.3 & 0.325 & 4.54 & $1 \cdot 1$ & 4.66 & 0.9 & 0.226 \\
\hline Self- efficacy & 8.99 & $2 \cdot 1$ & 9.43 & $2 \cdot 2$ & $0.014^{\star \star}$ & 8.65 & 1.9 & 8.52 & 1.6 & 0.453 \\
\hline \multicolumn{11}{|l|}{ Dietary practice } \\
\hline Breakfast & 3.47 & 1.8 & 3.92 & 1.8 & $0.002^{\star *}$ & 3.46 & $1 \cdot 7$ & 3.51 & 1.6 & 0.758 \\
\hline Carrying lunch to school & 1.6 & 0.6 & 3.33 & 0.8 & $<0.001^{\star \star \star}$ & 1.51 & 0.7 & 1.42 & 0.8 & 0.225 \\
\hline Family dietary habits & 7.02 & 1.9 & 7.44 & 1.7 & $0.005^{\star *}$ & $6 \cdot 88$ & $1 \cdot 8$ & 6.56 & 1.8 & 0.072 \\
\hline Fruits $\ddagger$ & $4 \cdot 18$ & $2 \cdot 8$ & 4.13 & $2 \cdot 2$ & 0.811 & 4.25 & 2.4 & 4.21 & $2 \cdot 2$ & 0.861 \\
\hline Vegetables§ & 5.98 & 2.5 & 7.56 & $2 \cdot 3$ & $<0.001^{\star \star *}$ & $6 \cdot 22$ & $2 \cdot 3$ & 6.34 & $2 \cdot 2$ & 0.564 \\
\hline High fat foods\| & 8.89 & 3.2 & 8.85 & $3 \cdot 1$ & 0.878 & $9 \cdot 12$ & $1 \cdot 3$ & 9.35 & 1.2 & 0.815 \\
\hline High sugar foods? & $11 \cdot 28$ & 3.7 & 11.96 & 2.9 & $0.014^{* *}$ & 11.98 & 3.3 & 11.67 & 2.9 & 0.621 \\
\hline High salt foodst & 10.94 & $2 \cdot 7$ & $11 \cdot 11$ & $2 \cdot 6$ & 0.434 & 11.34 & $2 \cdot 9$ & 11.58 & 1.9 & 0.718 \\
\hline \multicolumn{11}{|l|}{ Physical activity practice } \\
\hline $\begin{array}{l}\text { Moderate-to-vigorous } \\
\text { activity }\end{array}$ & 5.97 & $3 \cdot 8$ & $6 \cdot 71$ & $3 \cdot 6$ & $0.017^{\star *}$ & $6 \cdot 38$ & $2 \cdot 8$ & $6 \cdot 12$ & $2 \cdot 9$ & 0.355 \\
\hline Sedentary activity & 12.46 & 3.9 & $12 \cdot 16$ & 2.9 & 0.292 & 12.98 & $3 \cdot 1$ & $12 \cdot 71$ & $2 \cdot 8$ & 0.354 \\
\hline
\end{tabular}

${ }^{* *} P<0.05^{* * \star} P<0.001$

†Wafers, farsan (deep fried gram flour based salty snack), Frankie (wraps prepared with refined flour and stuffed with potatoes and vegetables), fried rice, hakka noodles, Maggi noodles.

‡Banana, apple, berries, citrus, papaya and melons.

$\S$ Carrot, green leafy vegetables, cauliflower/cabbage, salad.

॥Popular Indian snacks such as samosa, vada pav and pav bhaji and burger and pizza.

|Biscuit, cake, chocolates, carbonated beverages.

27.5 (SD 22.8) g, and $98.3(\mathrm{SD} 41 \cdot 1) \mathrm{ml}$, respectively. Significant improvements were reported in the mean daily intake of green leafy vegetables (58.9 (SD 18.4) g, $P<0.001$ ), chocolates (18.6 (SD 8.2) g, $P$ 0.006) and carbonated beverages (84.4 (SD 23.1), $P<0.001$ ) in EG but not in CG during post-intervention assessments. In EG, the daily consumption of Indian fried snacks, namely samosa and vada pav was 10.2 and $13.1 \%$ lower after 12 weeks of educational intervention as compared with CG. However, these improvements were not statistically significant.

\section{Participant ratings of instruction and teacher feedback}

A total of 276 participants in EG ( 145 from aided and 131 from private school) and seven teachers (four from aided and three from private school) completed the post-intervention feedback questionnaire. The majority reported 'strongly agreeing' to the statements such as 'I enjoyed learning about healthy eating habits and activity levels' (81\%), 'activities were fun and assignments were interesting' (73\%), 'teacher explained key concepts in detail' (76\%) and 'teacher was friendly and responded to all questions enthusiastically' ( $82 \%$ ). While $62 \%$ of participants from the aided school agreed that 'I am confident that I will be able to follow most of the healthy habits learned'; $77 \%$ of participants from the private school agreed that 'I am satisfied with the lessons and happy to be part of this program'. Teachers mentioned materials were informative, the catchy phrases and jingles made learning fun and speaking to parents was much needed. Suggestions included add dance or yoga sessions to the program, repeat sessions in the next academic year, conduct the same program for primary children and translate materials into other languages.

\section{Discussion}

The current study evaluated the impact of a behaviourally focused NE programme, referred to as HEAPS, on healthy eating habits and physical activity-related KAP among 
adolescents, aged 10-12 years. Significant improvements in the mean KAP scores were observed in EG but not in CG. These findings are in agreement with the results obtained from similar studies that reported significant improvements in NE intervention schools as compared with control schools ${ }^{(33,34,37,65)}$. Changes in attitudinal attributes beyond improvements in cognitive variables are documented to be important determinants of bringing changes in behaviours and practices ${ }^{(30,41,43)}$. The results of the current study indicated that the intervention was effective in improving knowledge regarding food groups, nutrients, non-communicable diseases and physical activity recommendations and changing the perceptions towards susceptibility and severity of the adverse consequences, perceived benefits, barriers and self-efficacy to adopt healthy eating habits and activity patterns.

The positive impact of the intervention on knowledge and attitudes can be explained by the active and interactive teaching approach that was employed in combination with an experiential learning method, facilitated through practical assignments and hands-on activities ${ }^{(40)}$. Each EG participant was provided with an activity book; this might have influenced the comprehension of key messages and led to enhanced motivations to learn. These results corroborate the findings of previous theory-based NE intervention studies that reported improvements in perceived benefits and self-efficacy of adolescents ${ }^{(38,47,50,55)}$.

The intervention led to improvements in eating habits such as frequency of breakfast and vegetable consumption, bringing lunch boxes to school, and mean scores of family dietary habits. The daily intake of green leafy vegetables increased and the consumption of chocolates and carbonated beverages reduced in EG. Item scores related to moderate-to-vigorous physical activities also showed improvements as compared with the CG. However, the within-group analysis showed that the post-intervention changes in certain dietary practices such as consumption of fruits and foods that are high in fat and salt content and practice items related to sedentary behaviours were not statistically significant. A systematic review of NE interventions indicated that changing dietary practices will require longer duration interventions ( $>1$ year) and modifications in foodservice policies to support a better provision of healthy foods in schools ${ }^{(42)}$. This can explain the unchanged variables in our study - a comparatively brief period of intervention and follow-up ( $<6$ months) and limited modifications employed in the school and home food environments of adolescents. Similar results of improvements in knowledge and attitude scores but minimal changes in dietary practices related to fruit and vegetable consumption have been reported in previous studies ${ }^{(31,53)}$. A systematic review observed that adolescents who had better knowledge had a better attitude, but improved attitude did not always lend to better practices related to physical activity ${ }^{(43)}$. Likewise, another large-scale obesity prevention intervention, eat well be active, reported limited improvements in indicators of attitudes and practices, although significant improvements were observed in teachers' skills and knowledge and learners' learning environments ${ }^{(66)}$.

Clearly, greater efforts are needed to motivate adolescents to adopt healthy eating behaviours and activity patterns in daily life. A systematic review of interventions aimed at improving physical activity levels and preventing excessive sedentary behaviours in school settings concluded that multi-level interventions that are behaviourally focused and introduce lifestyle education into regular school activities may bring significant improvements in the activity levels of adolescents ${ }^{(17)}$. These findings of previous studies and the results of our study indicate that bringing a change in diet and activity practices is difficult but possible through targeted behaviour change communication strategies and tailoring messages to the needs of the learning group.

Several studies have established that relevant $\mathrm{NE}$ should be provided early in life to influence present dietary choices and activity levels, to promote lifelong healthy behaviours and to reduce the burden of chronic diseases in adulthood ${ }^{(31,38,55)}$. In our study, the participants were 10-12 years old, a vulnerable but critical stage of early adolescence when autonomy in terms of food preferences and activity choices is progressively gained and the influences of peers and media start to become pronounced $^{(67)}$. While chronic diseases may take years to develop, the typical habits and behaviours that increase the risk of these diseases are initiated and established during adolescence ${ }^{(68)}$. Therefore, NE interventions that build on key messages around nutrition, regular physical activity and reduced sedentary activity and foster positive attitudes and self-efficacy become increasingly important during early adolescence.

Given the amount of time spent in schools by adolescents, implementing NE in schools presents an expedient and tactical way of positively influencing knowledge and attitudes and promoting healthy behaviours. The current nutrition and health education curriculum in secondary schools in India is minimal ${ }^{(51,69)}$. An outline of nutrition and healthy lifestyle-related learning objectives and structured guidance on how these topics should be taught and presented to the students, as part of the existing curriculum, is required to encourage positive attitudes and to improve the present and future health outcomes of adolescents in India.

It is evident from various school-based intervention studies that an adolescent's physical and social environment can act as important facilitators for supporting sustainable and significant behaviour changes ${ }^{(70,71)}$. Therefore, a concerted effort of policymakers to bring necessary changes in the school food environments and introduce curriculum-based and teacher delivered nutrition lessons 
at schools is warranted. Parents impart key influences on eating behaviours and activity choices of adolescents, so a greater involvement of parents will work as a catalyst to multiply the impact of interventions aimed at building skills and behaviours conducive to health promotion. Fostering better home food environments and involving peer leaders as change agents can further improve the outcomes of a NE programme ${ }^{(52,72)}$. Besides education tools and aids, the positive personal attributes of instructors may facilitate a caring relationship with participants and contribute to an improved programme impact.

To our knowledge, this NE programme is the first to investigate changes in nutrition and activity behaviours among adolescents in a school setting in Mumbai, India. NE interventions have been conducted in India ${ }^{(37,73)}$; however, few have included elaborate formative research to guide the intervention protocol or employed behaviour change theories to implement and evaluate the impact of education interventions. There are several strengths to the current study. We conducted a needs assessment to identify knowledge gaps and perceived barriers and facilitators to adopting desirable dietary and activity practices in adolescents. This was followed by formulating behaviour change objectives, selection of the appropriate theoretical framework to guide methods and subsequent development of the intervention protocol. The underlying theoretical framework of the HBM was employed to plan and implement the intervention programme, evidence-based behaviour change communication strategies, and innovative teaching aids and activities were included and a validated KAP survey was used to measure the changes from baseline to 12 weeks in the EG and CG. Also, the selection of the participants was done from private and aided schools to ensure that low and middle to high SES were represented in both EG and CG and the cluster randomised controlled study design contributed to the robustness of the study. Furthermore, participant experiences were explored to evaluate the perceived benefits of the intervention and a 2-month follow-up in a subsample of adolescents helped establish the sustainability of the impact of the intervention.

There are a few limitations too. The effectiveness of the education intervention described in the current study is based on self-reported responses to items measuring KAP. Although several measures of validity and reliability were evaluated to test the psychometric properties of the survey instrument, the continued interaction of the EG participants with the researchers may have inclined them to report what they learned and perceived to be favourable responses. However, it must be noted that social desirability bias is reported to be more common in interviews than survey modes of data collection. The finding that the positive impact of the intervention remained during the 2-month follow-up survey may also mitigate this limitation. Future research may adapt the study designs to include objective assessments of variables such as physical activity and sedentary behaviours and evaluate the influence of school and home food environments in modifying practices and behaviours of adolescents. The role of peer-led and teacher delivered NE sessions can also be explored in further studies.

In conclusion, the desirable changes in KAP related to eating habits and activity levels reflect the effectiveness of a theory-driven intervention in providing instructions that first improves knowledge and builds skills through interactive teaching methods and collaborative activities and then goes on to influence attitudes and practices. Since schools play a significant role in shaping the attitudes and practices of adolescents, relevant modifications in the school food environment such as improved availability of healthy foods and reduced accessibility to nutrient-poor and energy-dense snacks at school canteens are needed. The involvement of teachers and peer leaders in schools and the active support and participation of parents are also needed to initiate behaviour change towards healthy dietary habits, reduced sedentary behaviours and improved physical activity levels in adolescents in India.

The current study showed that adding 50 min per week of NE into the academic timetables can have positive effects on the knowledge, attitudes and health behaviours of adolescents. Integrating $\mathrm{NE}$ into a normal school day for adolescents in secondary education, adopting evidence-based lessons that entail discussions, critical thinking and activities and a fairly flexible curriculum that allows a customised information delivery method can improve knowledge, foster right attitudes and facilitate better eating and activity-related practices in Indian adolescents. An investment made to build positive attitudes towards health during adolescence may prove to be an investment that will reap rich dividends throughout the lifetime.

\section{Acknowledgements}

Acknowledgements: The authors would like to acknowledge the efforts of Dr. Jagdish Sharma for his assistance with statistical analysis and the field research team, Niki Shah, Tanvi Chipkar, Sonal Patil and Sharvari Gaikwad for their hard work. Our appreciation is also due to the principals of the institutes who provided permission to conduct the study and the homeroom/class teachers of grade 6 and grade 7 for their constant assistance. The authors acknowledge the valuable inputs and cooperation provided by the participants during the study. Financial support: This research received no specific grant from any funding agency, commercial or not-for-profit sectors. Conflict of interest: The authors declare no potential conflict of interest. Authorship: P.M. and J.M. formulated the research questions and designed the study; P.M. and P.V. supervised fieldwork. P.M. was responsible for data management, data analysis and drafting of the first draft of the manuscript. The 
draft was reviewed by J.M. and P.V. and the final revised manuscript was approved by all authors. Ethics of human subject participation: The current study was conducted according to the guidelines laid down in the Declaration of Helsinki and all procedures involving research study participants were approved by the Intersystem Biomedica Ethics Committee, Vile Parle West, Mumbai, India (version 2, dated 19 February 2019). Written informed consent was obtained from parents and written informed assent was obtained from the participants.

\section{Supplementary material}

For supplementary material accompanying this paper visit https://doi.org/10.1017/S1368980021000203

\section{References}

1. Sivagurunathan C, Umadevi R, Rama R et al. (2015) Adolescent health: present status and its related programmes in India. Are we in the right direction? J Clin Diagnostic Res 9 , LE01.

2. World Health Organization (2015) WHO Global Action Plan for the Prevention and Control of NCDs 2013-2020. Geneva: World Health Organization.

3. Kumar S \& Kelly AS (2017) Review of childhood obesity: from epidemiology, etiology, and comorbidities to clinical assessment and treatment. Mayo Clin Proc 92, 251-265.

4. Craigie AM, Lake AA, Kelly SA et al. (2011) Tracking of obesity-related behaviours from childhood to adulthood: a systematic review. Maturitas 70, 266-284.

5. Marks J, Barnett LM, Strugnell C et al. (2015) Changing from primary to secondary school highlights opportunities for school environment interventions aiming to increase physical activity and reduce sedentary behaviour: a longitudinal cohort study. Int J Behav Nutr Phys Act 12, 59.

6. Bailey C, Garg V, Kapoor D et al. (2018) Food choice drivers in the context of the nutrition transition in Delhi, India. J Nutr Educ Behav 50, 675-686.

7. Shayo FK (2019) Co-occurrence of risk factors for noncommunicable diseases among in-school adolescents in Tanzania: an example of a low-income setting of subSaharan Africa for adolescence health policy actions. BMC Public Health 19, 1-8.

8. Rathi N, Riddell L \& Worsley A (2018) Parents' and teachers' views of food environments and policies in Indian private secondary schools. Int JEnviron Res Public Health 15, 1532.

9. Jayawardena R, Ranasinghe P, Wijayabandara $\mathrm{M}$ et al. (2016) Nutrition transition and obesity among teenagers and young adults in South Asia. Curr Diabetes Rev 13, 444-451.

10. Misra A, Singhal N, Sivakumar B et al. (2011) Nutrition transition in India: secular trends in dietary intake and their relationship to diet-related non-communicable diseases. $J$ Diabetes 3, 278-292.

11. Rathi N, Riddell L \& Worsley A (2018) Urban Indian adolescents practise unhealthy dietary behaviors. Br Food J 120, $1657-1665$.

12. Mehta K, Mazumdar V, Patel SV et al. (2014) Dietary pattern of schoolgoing adolescents in Urban Baroda, India. $J$ Heal Popul Nutr 31, 490.

13. Moreno LA, Rodríguez G, Fleta J et al. (2010) Trends of dietary habits in adolescents. Crit Rev Food Sci Nutr 50, 106-112.

14. Wolfenden L, Nathan NK, Sutherland R et al. (2017) Strategies for enhancing the implementation of school-based policies or practices targeting risk factors for chronic disease. Cochrane Database Syst Rev. Published online: 29 November 2017. doi: 10.1002/14651858.CD011677.

15. Twisk JWR (2001) Physical activity guidelines for children and adolescents a critical review. Sport Med 31, 617-627.

16. Must A \& Tybor DJ (2005) Physical activity and sedentary behavior: a review of longitudinal studies of weight and adiposity in youth. Int J Obes 29, S84-S96.

17. Biddle SJH, Pearson N, Ross GM et al. (2010) Tracking of sedentary behaviours of young people: a systematic review. Prev Med 51, 345-351.

18. Craggs C, Corder K, Van Sluijs EMF et al. (2011) Determinants of change in physical activity in children and adolescents: a systematic review. Am J Prev Med 40, 645-658.

19. Singh AK, Maheshwari A, Sharma N et al. (2006) Lifestyle associated risk factors in adolescents. Indian J Pediatr 73, 901-906.

20. Esht V, Midha D, Chatterjee S et al. (2018) A preliminary report on physical activity patterns among children aged 8-14 years to predict risk of cardiovascular diseases in Malwa region of Punjab. Indian Heart J 70, 777-782.

21. Swaminathan S \& Vaz M (2013) Childhood physical activity, sports and exercise and noncommunicable disease: a special focus on India. Indian J Pediatr 80, 63-70.

22. Jagadesan S, Harish R, Miranda P et al. (2014) Prevalence of overweight and obesity among school children and adolescents in Chennai. INDIAN Pediatr 51, 544-549.

23. Branca F, Lartey A, Oenema S et al. (2019) Transforming the food system to fight non-communicable diseases. BMJ 364, 1296.

24. Popkin BM, Adair LS \& Ng SW (2012) Global nutrition transition and the pandemic of obesity in developing countries. Nutr Rev 70, 3-21.

25. Ranjani H, Mehreen TS, Pradeepa R et al. (2016) Epidemiology of childhood overweight \& obesity in India: a systematic review. Indian J Med Res 143, 160.

26. Poti JM, Duffey KJ \& Popkin BM (2014) The association of fast food consumption with poor dietary outcomes and obesity among children: Is it the fast food or the remainder of the diet? Am J Clin Nutr 99, 162-171.

27. Kumar S, Ray S, Roy D et al. (2017) Exercise and eating habits among urban adolescents: a cross-sectional study in Kolkata, India. BMC Public Health 17, 468.

28. Kigaru DMD, Loechl C, Moleah Tet al. (2015) Nutrition knowledge, attitude and practices among urban primary school children in Nairobi City, Kenya: a KAP study. BMC Nutr 1, 1-8.

29. Swaminathan S, Thomas T, Kurpad AV et al. (2009) Perceptions of healthy eating: a qualitative study of schoolgoing children in south India. Health Educ J 68, 94-110.

30. Cown MH, Grossman BM \& Giraudo SQ (2017) Nutrition education intervention to improve nutrition-related knowledge, attitudes, and behaviors for Hispanic children. Ecol Food Nutr 56, 493-513.

31. Mamba NPS, Napoles L \& Mwaka NM (2019) Nutrition knowledge, attitudes and practices of primary school children in Tshwane Metropole, South Africa. African J Prim Heal Care Fam Med 11, 1-7.

32. Kupolati MD, MacIntyre UE, Gericke GJ et al. (2019) A contextual nutrition education program improves nutrition knowledge and attitudes of South African teachers and learners. Front Public Heal 7, 258.

33. Friel S, Kelleher C, Campbell P et al. (1999) Evaluation of the Nutrition Education at Primary School (NEAPS) programme. Public Health Nutr 2, 549-555.

34. Shilts MK, Lamp C, Horowitz M et al. (2009) Pilot Study: EatFit impacts sixth graders' academic performance on achievement of mathematics and English education standards. J Nutr Educ Behav 41, 127-131.

35. Pérez-Rodrigo C \& Aranceta J (2003) Nutrition education in schools: experiences and challenges. Eur J Clin Nutr 57, S82-S85. 
36. Meiklejohn S, Ryan L \& Palermo C (2016) A systematic review of the impact of multi-strategy nutrition education programs on health and nutrition of adolescents. J Nutr Educ Behav $\mathbf{4 8}$, 631-646.e1.

37. Singhal N, Misra A, Shah P et al. (2010) Effects of controlled school-based multi-component model of nutrition and lifestyle interventions on behavior modification, anthropometry and metabolic risk profile of urban Asian Indian adolescents in North India. Eur J Clin Nutr 64, 364-373.

38. Silveira JAC, Taddei JAAC, Guerra PH et al. (2011) Effectiveness of school-based nutrition education interventions to prevent and reduce excessive weight gain in children and adolescents: a systematic review. $J$ Pediatr 87, 382-392.

39. Lawlor DA, Kipping RR, Anderson EL et al. (2016) Active for Life Year 5: a cluster randomised controlled trial of a primary school-based intervention to increase levels of physical activity, decrease sedentary behaviour and improve diet. Public Heal Res 4, 1-156.

40. Dudley DA, Cotton WG \& Peralta LR (2015) Teaching approaches and strategies that promote healthy eating in primary school children: a systematic review and meta-analysis. Int J Behav Nutr Phys Act 12, 1-26.

41. Worsley A (2002) Nutrition knowledge and food consumption: can nutrition knowledge change food behaviour? Asia Pac J Clin Nutr 11, Suppl. 3, S579-S585.

42. Ashton LM, Sharkey T, Whatnall MC et al. (2019) Effectiveness of interventions and behaviour change techniques for improving dietary intake in young adults: a systematic review and meta-analysis of RCTs. Nutrients $\mathbf{1 1}$, 825.

43. Samdal GB, Eide GE, Barth T et al. (2017) Effective behaviour change techniques for physical activity and healthy eating in overweight and obese adults; systematic review and meta-regression analyses. Int J Behav Nutr Phys Act 14, 42 .

44. Michie S, Carey RN, Johnston M et al. (2018) From theoryinspired to theory-based interventions: A protocol for developing and testing a methodology for linking behaviour change techniques to theoretical mechanisms of action. Ann Behav Med 52, 501-512.

45. Contento I (1995) The effectiveness of nutrition education and implications for nutrition education policy, programs and research; a review of research: Special issue. J Nutr Educ Series 27(6), 284-418.

46. Ghaffari M, Esmaillzadeh A, Tavassoli E et al. (2012) Effect of health belief model based intervention on promoting nutritional behaviors about osteoporosis prevention among students of female middle schools in Isfahan, Iran. $J E d u c$ Health Promot 1, 14.

47. Keshani P, Hossein Kaveh M, Faghih S et al. (2019) Improving diet quality among adolescents, using health belief model in a collaborative learning context: a randomized field trial study. Health Educ Res 34, 279-288.

48. Naghashpour M, Shakerinejad G, Lourizadeh MR et al. (2014) Nutrition education based on health belief model improves dietary calcium intake among female students of junior high schools. J Heal Popul Nutr 32, 420-429.

49. Glanz K \& Bishop DB (2010) The role of behavioral science theory in development and implementation of public health interventions. Annu Rev Public Health 31, 399-418.

50. Salem GM \& Said RM (2018) Effect of health belief model based nutrition education on dietary habits of secondary school adolescent girls in Sharkia Governorate. Egypt $J$ Commun Med 36, 35-47.

51. Rathi N, Riddell L \& Worsley A (2017) Secondary school students' views of food and nutrition education in Kolkata, India. Health Educ 117, 310-322.

52. Pearson N, Griffiths P, Biddle SJH et al. (2017) Individual, behavioural and home environmental factors associated with eating behaviours in young adolescents. Appetite 112, 35-43.

53. Scherr RE, Linnell JD, Dharmar M et al. (2017) A multicomponent, school-based intervention, the shaping healthy choices program, improves nutrition-related outcomes. $J$ Nutr Educ Behav 49, 368-379.e1.

54. Karki A, Shrestha A \& Subedi N (2019) Prevalence and associated factors of childhood overweight/obesity among primary school children in urban Nepal. BMC Public Health 19, 1055.

55. Tilles-Tirkkonen T, Nuutinen O, Sinikallio S et al. (2018) Theory-informed nutrition education curriculum Tools For Feeling Good promotes healthy eating patterns among fifth grade pupils: cross-sectional study. J Hum Nutr Diet 31, 647-657.

56. Murimi MW, Moyeda-Carabaza AF, Nguyen B et al. (2018) Factors that contribute to effective nutrition education interventions in children: a systematic review. Nutr Rev 76, 553-580.

57. Diep CS, Chen TA, Davies VF et al. (2014) Influence of behavioral theory on fruit and vegetable intervention effectiveness among children: a meta-analysis. J Nutr Educ Behav 46, 506-546.

58. Sullivan GM \& Feinn R (2012) Using effect size: or why the $P$ value is not enough. J Grad Med Educ 4, 279-282.

59. Teo CH, Chin YS, Lim PY et al. (2019) School-based intervention that integrates nutrition education and supportive healthy school food environment among Malaysian primary school children: a study protocol. BMC Public Health 19, 1427.

60. Saraf DS, Gupta SK, Pandav CS et al. (2015) Effectiveness of a school based intervention for prevention of noncommunicable diseases in middle school children of rural north India: a randomized controlled trial. Indian J Pediatr 82, 354-362.

61. Moitra P \& Madan J (2020) Perceived barriers and facilitators of healthy eating and physical activity: focus groups with children, parents and teachers in Mumbai, India. Int $J$ Community Med Public Heal 7, 2363.

62. Moitra P, Verma P \& Madan J (2021) Development and validation of a questionnaire measuring knowledge, attitudes, and practices (KAP) to healthy eating and activity patterns in school children (HEAPS). Nutr Health. doi: 10.1177/ 0260106020982356

63. Shaikh NI, Patil SS, Halli S et al. (2016) Going global: Indian adolescents' eating patterns. Public Health Nutr 19, 27992807.

64. National Institute of Nutrition (2011) Dietary Guidelines for Indians: a Manual. https://www.nin.res.in/downloads/ DietaryGuidelinesforNINwebsite.pdf (accessed May 2020).

65. Kupolati MD, MacIntyre UE, Gericke GJ et al. (2019) A contextual nutrition education program improves nutrition knowledge and attitudes of South African teachers and learners. Front Public Heal 7, 258.

66. Magarey AM, Pettman TL, Wilson A et al. (2013) Changes in primary school children's behaviour, knowledge, attitudes, and environments related to nutrition and physical activity. ISRN Obes 2013, 1-10.

67. Koehn S, Gillison F, Standage M et al. (2016) Life transitions and relevance of healthy living in late adolescence. J Health Psychol 21, 1085-1095.

68. Ssewanyana D, Abubakar A, van Baar A et al. (2018) Perspectives on underlying factors for unhealthy diet and sedentary lifestyle of adolescents at a Kenyan Coastal setting. Front Public Heal 6, 11.

69. Rathi N, Riddell L \& Worsley A (2019) Parents' and teachers' critique of nutrition education in Indian secondary schools. Health Educ 119, 150-164.

70. Welker E, Lott M \& Story M (2016) The school food environment and obesity prevention: progress over the last decade. Curr Obes Rep 5, 145-155. 
71. He M, Tucker P, Gilliland J et al. (2012) The influence of local food environments on adolescents' food purchasing behaviors. Int J Environ Res Public Health 9, 1458-1471.

72. Story M, Lytle LA, Birnbaum AS et al. (2002) Peer-led, schoolbased nutrition education for young adolescents: feasibility and process evaluation of the TEENS study. J Sch Health 72, 121-127.
73. Raghunatha Rao D, Vijayapushpam T, Subba Rao GM et al. (2007) Dietary habits and effect of two different educational tools on nutrition knowledge of school going adolescent girls in Hyderabad, India. Eur J Clin Nutr 61, 1081-1085. 